\title{
Long-Term Stability of Benefits of Cognitive Behavioral Therapy for Obsessive Compulsive Disorder Depends on Symptom Remission During Treatment
}

\author{
Björn Elsner ${ }^{\mathrm{a}}$, Frieder Wolfsberger ${ }^{\mathrm{a}}$, Jessica Srp ${ }^{\mathrm{a}}$, Antonia Windsheimer ${ }^{\mathrm{a}}$, Laura Becker ${ }^{\mathrm{a}}$, \\ Tanja Jacobi ${ }^{\mathrm{a}}$, Norbert Kathmann ${ }^{\mathrm{a}}$, Benedikt Reuter ${ }^{\mathrm{a}}$
}

[a] Department of Psychology, Humboldt-Universität zu Berlin, Berlin, Germany.

Clinical Psychology in Europe, 2020, Vol. 2(1), Article e2785, https://doi.org/10.32872/cpe.v2i1.2785

Received: 2019-09-03 • Accepted: 2020-02-04 • Published (VoR): 2020-03-31

Handling Editor: Winfried Rief, Philipps-University of Marburg, Marburg, Germany

Corresponding Author: Björn Elsner, Humboldt-Universität zu Berlin, Rudower Chaussee 18, 12489 Berlin, Germany, Tel.: 004930 2093-9338. E-mail: bjoern.elsner@hu-berlin.de

\begin{abstract}
Background: Cognitive behavioral therapy (CBT) is an effective treatment for obsessivecompulsive disorder (OCD) and may afford stable long-term improvements. It is not clear, however, how stability or symptom recurrence can be predicted at the time of termination of CBT.

Method: In a 1-year follow-up intention-to-treat study with 120 OCD patients receiving individual $\mathrm{CBT}$ at a university outpatient unit, we investigated the predictive value of international consensus criteria for response only (Y-BOCS score reduction by at least 35\%) and remission status (Y-BOCS score $\leq 12)$. Secondly, we applied receiver-operating characteristic $(\mathrm{ROC})$ curves in order to find an optimal cut-off score to classify for deterioration and for sustained gains.

Results: Response only at post-treatment increased the likelihood of deterioration at follow-up compared to remission at an odds ratio of 8.8. Moreover, ROC curves indicated that a posttreatment score of $\geq 13$ differentiated optimally between patients with and without symptom deterioration at follow-up assessment. The optimal cut-off score to classify for any sustained gains (response, remission, or both) at follow-up relative to baseline was 12. Importantly, previous findings of generally high long-term symptom stability after treatment in OCD could be replicated. Conclusion: The findings highlight the clinical importance of reaching remission during CBT, and suggest that a recently published expert consensus for defining remission has high utility.
\end{abstract}

\section{Keywords}

obsessive-compulsive disorder, Y-BOCS, cut-off score, expert consensus, follow-up 


\section{Highlights}

- A 1-year follow-up study with OCD patients having received a CBT trial was conducted.

- Achieving a Y-BOCS score $\leq 12$ at termination of treatment decreases the risk of future deterioration.

- The study supports a rationale to treat OCD patients until reaching remission status.

- The study confirms the criterion for remission in OCD recently published as an expert consensus.

Cognitive behavioral therapy (CBT) is an effective treatment for obsessive-compulsive disorder (OCD). Its efficacy in randomized-controlled trials (RCT; Olatunji, Davis, Powers, \& Smits, 2013; Öst, Havnen, Hansen, \& Kvale, 2015) and its effectiveness in routine clinical practice (Hans \& Hiller, 2013) have been confirmed in meta-analyses. According to follow-up data, treatment gains are largely maintained after treatment, but in randomized controlled trials, slight increases of average symptom scores from post-treatment to follow-up are observed at group level (Olatunji et al., 2013; Öst et al., 2015). However, follow-up data from routine care are still rare, especially for individual outpatient therapy (Cabedo, Carrió, \& Belloch, 2018; Hans \& Hiller, 2013; Hansen, Kvale, Hagen, Havnen, \& Öst, 2019).

The Yale-Brown Obsessive-Compulsive Scale (Y-BOCS) interview (Goodman et al., 1989a; Goodman et al., 1989b) has been established as the "gold standard" to measure OCD symptom severity, and is commonly used as a primary outcome measure (Óst et al., 2015). Effect sizes based on Y-BOCS group mean scores are therefore useful for comparisons between studies and interventions, and allow observing within-group changes. However, group mean scores do not reflect individual improvement (Hiller, Schindler, Andor, \& Rist, 2011; Jacobson, Follette, \& Revenstorf, 1984), which is especially important in research on routine clinical practice. In order to address this issue, Jacobson and Truax (1991) proposed a definition of clinically significant improvement by combining statistically significant changes in individual symptoms (Reliable Change Index, RCI) with subclinical symptom levels. This makes it possible to determine individual response (without remission), remission, and deterioration. Since clinically significant change depends on the reliability of the measure and the variance in the relevant population, cut-off scores for remission varied between 7 and 16 across published studies (Öst et al., 2015). Subsequently, Mataix-Cols et al. (2016) published an international expert consensus on change assessment in $\mathrm{OCD}$, in which treatment response was defined as a reduction in Y-BOCS scores by at least $35 \%$ and an improvement score of 1 ("very much improved") or 2 ("much improved") on the Clinical Global Impression scale (CGI, Guy, 1976). For remission, a Y-BOCS score of < 13 and CGI severity ratings of 1 ("normal, 
not at all ill") or 2 ("borderline mentally ill") must be achieved. These criteria have been adopted in recent research (Hansen et al., 2019) and may prove influential for future clinical decisions in OCD treatment. Yet, it remains unclear whether these consensus criteria have clinical utility and are able to predict individual long-term stability.

Prediction of post-treatment response and remission on the basis of pre-treatment Y-BOCS scores has been investigated by means of signal detection analyses (Farris, McLean, Van Meter, Simpson, \& Foa, 2013). Criteria evaluation for predicting outcome at follow-up, however, is missing. Prospective studies on depressive disorder and social phobia suggest that incomplete remission at post-treatment predicts relapse at follow-up (Judd et al., 1998; Paykel et al., 1995; Van Ameringen et al., 2003). In line with these results, two studies with OCD patients have shown that "partial remission" compared to "full remission" at the end of treatment predicts relapse during follow-up periods of one to five years (Braga, Cordioli, Niederauer, \& Manfro, 2005; Braga, Manfro, Niederauer, \& Cordioli, 2010; Eisen et al., 2013). One of these studies (Eisen et al., 2013), however, did not use Y-BOCS scores for the evaluation of clinical status. In the other, full remission required a Y-BOCS score of < 8 (Braga et al., 2005; Braga et al., 2010), which is much stricter than the consensus Y-BOCS cut-off score for remission $(\leq 12)$. It is therefore unclear whether the protective effect of "full remission" can also be found when applying the less strictly defined remission criterion. Prediction of long-term stability is of major importance for clinical practice, because under routine conditions the criterion for terminating individual psychotherapy is often not specified in advance. Treatment may be continued until a "good enough level" (GEL) is achieved (Barkham et al., 2006; Falkenström, Josefsson, Berggren, \& Holmqvist, 2016), which is often defined subjectively by patient and therapist. Clinical decisions, however, should also be informed by empirical research. In addition to testing the predictive value of categorical variables such as remission or response, it is also worthwhile to determine the exact post-treatment Y-BOCS scores that separate patients with stable treatment gains from those with loss of gains in the follow-up period, or patients with long-term improvements in relation to pre-treatment levels from those without such improvements. If good prediction is possible on the basis of a single, widely-used and easy-to-apply instrument, the cut-off scores can inform clinical decisions on whether to terminate or to continue CBT.

In the present study, we conducted a 1-year follow-up assessment in a relatively large sample of OCD patients, who had received individual CBT under routine conditions of the German health care system. Our main goals were: 1.) testing whether patients achieving the consensus Y-BOCS cut-off score for remission at post-treatment are less likely to experience significant symptom increase at follow-up compared to unremitted responders, 2.) determining a post-treatment Y-BOCS cut-off score that differentiates optimally between patients who deteriorate from post-treatment to follow-up and those whose initial improvement remains stable, and 3.) determining a post-treatment Y-BOCS cut-off score that predicts for any sustained gains (response, remission, or both) at 
follow-up. A secondary aim was to provide further data for evaluations of average and individual symptom changes from pre- and post-treatment to follow-up in a treatment setting typical for routine care in many countries.

\section{Method}

\section{Participants}

Study participants had terminated individual cognitive behavioral therapy (CBT) at a university outpatient unit (Hochschulambulanz für Psychotherapie und Psychodiagnostik der Humboldt-Universität zu Berlin) between December 2013 and May 2017. Referrals to the outpatient unit were made according to routine clinical care procedures. Patients who prematurely discontinued CBT (non-completers) were not excluded and the last observation was carried forward to estimate post-treatment scores (interim-assessments were done every 20 sessions). General study inclusion criteria were: primary diagnosis of OCD, age between 18 and 70 years, and a minimum pre-treatment Y-BOCS total score of 16 . Due to general admission policies of the outpatient unit, patients with comorbid psychotic disorders, borderline personality disorder, or substance dependency (life time) were not referred. Three patients were excluded from analysis due to missing Y-BOCS-data at both pre- and post-treatment. During the study period, a total of 207 patients fulfilled the inclusion criteria and were contacted by telephone for follow-up assessments. Among these, 51 (24.6\%) patients could not be reached and $36(17.4 \%)$ declined to participate. 120 patients participated in the phone interview $(58.0 \%$ of the total sample), and 96 of them completed additional online questionnaires ( $46.4 \%$ of the total sample).

Participants ( $n=120,75$ female, 104 therapy completers) and non-participants $(n=87$, 49 female, 70 therapy completers) in the follow-up interview did not differ significantly in terms of gender $(p=.392)$, therapy completer status $(p=.252)$, or other demographic and clinical variables (see Table 1). For both participants and non-participants, the most common comorbid mental disorders were present or remitted depressive disorders and anxiety disorders. Twenty-four patients of the total sample suffered from personality disorders (see Table 2). 73 patients took psychotropic medications at admission (35.3\%), 55 at post-treatment (26.6\%); the most common medications were selective serotonin reuptake inhibitors (SSRIs) and other antidepressants. The study protocol was approved by the local review board of Humboldt-Universität zu Berlin (protocol number 2016-33) and met the ethical standards of the revised Declaration of Helsinki. All participants provided written informed consent. 
Table 1

Demographic and Clinical Variables of Participants and Non-Participants in Follow-up Assessments

\begin{tabular}{|c|c|c|c|c|c|c|c|}
\hline \multirow[b]{2}{*}{ Variable } & \multicolumn{2}{|c|}{$\begin{array}{c}\text { Participants } \\
\text { Assessment } t_{\mathrm{FU}}\end{array}$} & \multicolumn{2}{|c|}{$\begin{array}{l}\text { Non-Participants } \\
\text { Assessment } t_{\mathrm{FU}}\end{array}$} & \multicolumn{3}{|c|}{$\begin{array}{l}t \text {-test for independent } \\
\text { samples }\end{array}$} \\
\hline & $n$ & $M(S D)$ & $n$ & $M(S D)$ & $d f$ & $t$ & $p$ \\
\hline Age & 120 & $32.3(9.5)$ & 87 & $31.5(9.9)$ & 181.0 & 0.59 & .558 \\
\hline Age of symptom onset & 109 & $17.1(8.8)$ & 81 & $17.1(7.6)$ & 183.2 & 0.02 & .986 \\
\hline Age of disorder onset & 110 & $23.1(9.6)$ & 78 & $22.4(8.5)$ & 117.3 & 0.58 & .558 \\
\hline Duration of therapy (hours) & 119 & $41.0(17.6)$ & 87 & $42.3(20.7)$ & 167.4 & -0.45 & 653 \\
\hline Socio-economic status & 112 & $9.6(3.7)$ & 79 & $9.2(4.2)$ & 154.2 & 0.77 & .443 \\
\hline GAF $t_{\text {pre }}$ & 118 & $55.8(10.1)$ & 86 & $53.3(11.2)$ & 171.0 & 1.66 & .099 \\
\hline Y-BOCS $t_{\text {pre }}$ & 120 & $23.3(4.6)$ & 87 & $24.4(4.7)$ & 182.0 & -1.74 & .083 \\
\hline Y-BOCS $t_{\text {post }}$ & 120 & $11.9(7.3)$ & 87 & $13.7(7.7)$ & 178.8 & -1.69 & .092 \\
\hline OCI-R $t_{\text {pre }}$ & 118 & $27.1(13.0)$ & 87 & $29.4(12.4)$ & 190.1 & -1.31 & .193 \\
\hline OCI-R $t_{\text {post }}$ & 120 & $14.4(12.0)$ & 85 & $17.7(13.5)$ & 167.2 & -1.78 & .078 \\
\hline BDI-II $t_{\text {pre }}$ & 119 & $18.9(11.2)$ & 87 & $20.4(10.8)$ & 188.8 & -0.97 & .336 \\
\hline BDI-II $t_{\text {post }}$ & 120 & $9.8(8.7)$ & 84 & $10.9(11.3)$ & 148.6 & -0.78 & .438 \\
\hline BSI-GSI t & 119 & $0.98(0.5)$ & 87 & $1.01(0.6)$ & 178.0 & -0.37 & .712 \\
\hline BSI-GSI $t_{\text {post }}$ & 120 & $0.60(0.5)$ & 85 & $0.70(0.6)$ & 163.2 & -1.17 & .245 \\
\hline
\end{tabular}

Note. GAF = Global Assessment of Functioning; Y-BOCS = Yale-Brown Obsessive-Compulsive Scale interview score; OCI-R = Obsessive Compulsive Inventory - Revised; BDI-II = Beck Depression Inventory II; BSI-GSI = Global Severity Index of the Brief Symptom Inventory; pre = pre-treatment; post = post-treatment; FU = 1-year follow-up.

\section{Table 2}

Most Common Comorbid Mental Disorders and Medication Status at $t_{\text {pre }}$ and $t_{\text {post }}$.

\begin{tabular}{|c|c|c|c|c|}
\hline \multirow[b]{2}{*}{ Condition } & \multicolumn{2}{|c|}{ Participants Assessment $t_{\mathrm{FU}}$} & \multicolumn{2}{|c|}{ Non-Participants Assessment $t_{\mathrm{FU}}$} \\
\hline & $n$ & $\%$ & $n$ & $\%$ \\
\hline$\geq 1$ comorbid mental disorder & 76 & 63.3 & 51 & 58.6 \\
\hline present depressive disorder & 40 & 33.3 & 29 & 33.3 \\
\hline remitted depressive disorder & 28 & 23.3 & 20 & 23.0 \\
\hline any anxiety disorder & 41 & 34.2 & 15 & 17.2 \\
\hline Personality disorder & 12 & 10.0 & 12 & 13.8 \\
\hline Psychotropic medications $t_{\text {pre }}$ & 45 & 37.5 & 28 & 32.2 \\
\hline Psychotropic medications $t_{\text {post }}$ & 35 & 29.2 & 20 & 23.0 \\
\hline
\end{tabular}

Note. pre = pre-treatment; post $=$ post-treatment; FU = 1-year follow-up. 


\section{Treatment}

CBT was administered by nineteen licensed psychotherapists, who had completed at least three years of training in CBT. Treatments were bound to the general conditions for psychotherapy in the public German health care system. The legal framework allowed up to 66.7 hours ( 80 units of 50 minutes each) per treatment. Therapists were instructed to apply CBT including exposure and response prevention (ERP) according to the national guideline for evidence-based treatment (Hohagen, Wahl-Kordon, Lotz-Rambaldi, \& Muche-Borowski, 2014). Adherence was not formally controlled and treatment was not manualized, but therapists received weekly supervision by one of four experienced CBT therapists. Therapy sessions usually lasted 50 minutes and took place once or twice weekly, yet therapists were free to adjust session length when implementing exposure and to reduce session frequency at the end of treatment. Treatment was terminated by consensus of patient and therapist based on clinical criteria. Patients who abandoned treatment without the approval of their therapist were classified as non-completers.

\section{Assessment}

One-year follow-up status of patients $\left(t_{\mathrm{FU}}\right)$ was assessed by telephone-based interviews and internet-based self-report questionnaires. Analyses also included data from routine assessments at admission ( $\left.t_{\text {pre }}\right)$ and termination of therapy $\left(t_{\text {post }}\right)$, and for non-completers, from interim-assessments.

Telephone interviews were conducted by trained master level psychology students, who were supervised by an experienced psychotherapist (B.R.). Interviews included the German version of the Y-BOCS interview to assess OCD symptom severity (Goodman et al., 1989a; Goodman et al., 1989b; Hand \& Büttner-Westphal, 1991). Internet-based assessments included the Obsessive Compulsive Inventory - Revised (OCI-R, Foa et al., 2002) as a secondary outcome measure of OCD symptoms, the Beck Depression Inventory II (BDI-II, Beck, Steer, \& Brown, 1996) to measure current depression, and the Brief Symptom Inventory (BSI, Derogatis \& Melisaratos, 1983) to assess general psychological distress using its Global Severity Index.

Routine assessments at admission ( $\left.\mathrm{t}_{\text {pre }}\right)$ included the German version of the Structured Clinical Interviews for DSM-IV mental disorders and personality disorders (SCID-I, SCID-II, First, Gibbon, Spitzer, Williams, \& Benjamin, 1997; First, Spitzer, Gibbon, \& Williams, 1995), and a socio-economic status scale (Lampert \& Kroll, 2009). In order to assess symptom course, Y-BOCS interview, OCI-R, BDI-II, BSI, the clinical global impression scale (CGI, Guy, 1976) and the global assessment of functioning (GAF, Jones, Thornicroft, Coffey, \& Dunn, 1995) were administered before the first and after the final therapy session. Interim assessments were conducted every 20 sessions and used to estimate post-treatment data for non-completers without post-treatment assessments ( $n=10$; last-observation-carried-forward method). Interim assessments were also used 
to estimate post-treatment scores for four therapy completers with missing data. All clinical interviews at admission and post-treatment were conducted by trained clinical psychologists.

\section{Data Analysis}

We analyzed data using R version 1.0.44. Participants and non-participants were compared using independent two sample $t$-tests (two-sided). Fisher's exact test was applied to compare nominal data. Effect sizes were calculated using Cohen's $d$ with pooled standard deviations. Changes over time were compared with paired $t$-tests (two-sided). We used the expert consensus criteria (Mataix-Cols et al., 2016) for Y-BOCS scores to define remission (total score $\leq 12$ ), response (reduction $\geq 35 \%$ ), and non-response (reduction $<35 \%$ ), but did not apply the CGI improvement scale (see also Hansen et al., 2019). We used the Reliable Change Index (RCI, Jacobson et al., 1984) to define statistically meaningful deterioration (e.g. Bablas, Yap, Cunnington, Swieca, \& Greenwood, 2016; Han, Geffen, Browning, Kenardy, \& Geffen, 2011; Kraus, Castonguay, Boswell, Nordberg, \& Hayes, 2011). To calculate the RCI, an internal consistency of $\alpha=.79$ (Moritz et al., 2002) was used as the reliability of the Y-BOCS. Stability was defined as the absence of significant deterioration. Logistic regression analysis was used to contrast response without remission (response only) and remission at post-treatment to predict deterioration at follow-up. As we were interested in stability after initial improvement, patients with no response during treatment were not considered in this analysis. Additionally, we applied receiver-operating characteristic (ROC) curves using R package OptimalCutpoints (López-Ratón, Rodríguez-Álvarez, Cadarso-Suárez, \& Gude-Sampedro, 2014) in order to find the best post-treatment Y-BOCS score classifying for deterioration versus stability at follow-up. ROC curves were also used to find the optimal post-treatment cut-off score classifying for sustained gains (response, remission, or both; $n=77$ ) at follow-up. The score that reached a maximum Youden index $(\mathrm{J}=$ Sensitivity + Specificity - 1; Youden, 1950) was considered as optimal cut-off.

\section{Results}

\section{Average Symptom Change}

On group level, the Y-BOCS score decreased significantly from pre-treatment to posttreatment, $t(119)=17.23, p<.001$, with a mean reduction of 11.4 points and a large effect size of Cohen's $d=1.87$ (Figure 1a, Table 3). Symptom severity was also significantly reduced from pre-treatment to one-year follow-up, $t(119)=13.75, p<.001, d=1.46$. The increase of the mean Y-BOCS score from post-treatment to follow-up was small, but close to significance, $t(119)=-1.79 ; p=.076, d=-0.12$ (see Figure 1a). 


\section{Figure 1}

Average and Individual Symptom Change

a

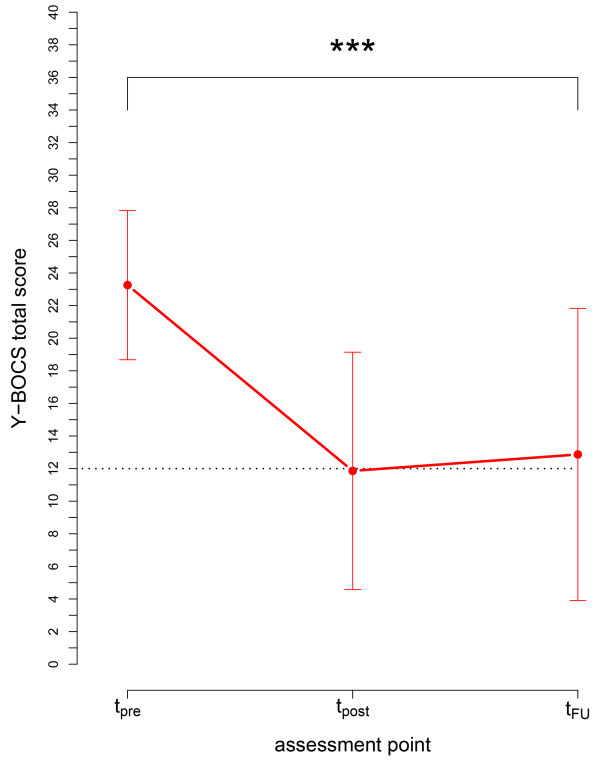

b

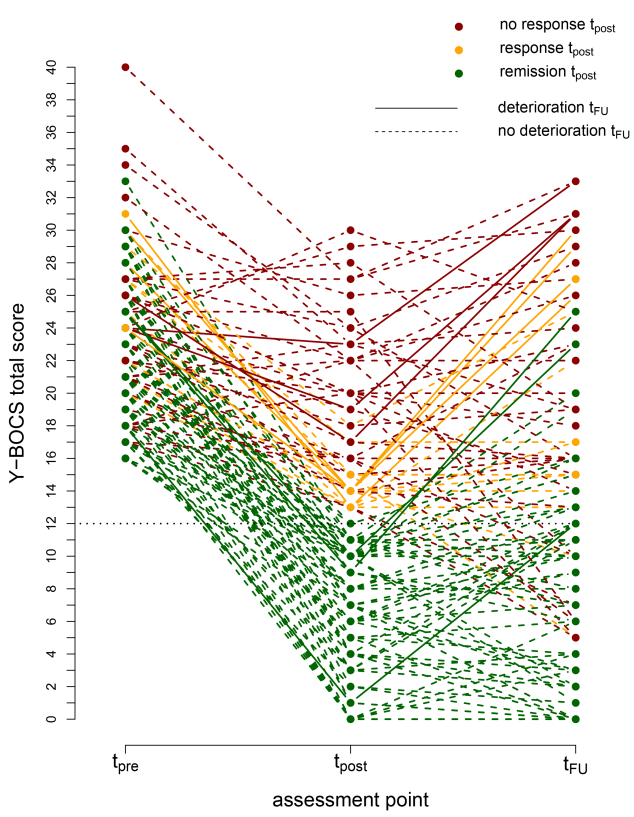

Note. a) Mean Y-BOCS total scores at pre-treatment $\left(\mathrm{t}_{\mathrm{pre}}\right)$, post-treatment $\left(\mathrm{t}_{\mathrm{post}}\right)$ and follow-up ( $\left.\mathrm{t}_{\mathrm{FU}}\right)$. b) Individual remission, response only and non-response at post-treatment (according to the expert consensus) and significant deterioration (according to Reliable Change Index) from post-treatment to follow-up. Error bars indicate standard deviations.

$* * * p<.001$.

Similarly, secondary outcome parameters showed significant reductions from pre-treatment to post-treatment (OCI-R: $t(234)=7.82 ; p<.001, d=1.01$; BDI-II: $t(222.99)=7.03$; $p$ $<.001, d=0.91$ and BSI-GSI: $t(236.01)=5.62 ; p<.001, d=0.73)$, and from pre-treatment to follow-up (OCI-R: $t(208.32)=8.40, p<.001, d=1.14$; BDI-II: $t(196.88)=4.15 ; p<.001$, $d=0.57$; and BSI-GSI: $t(207.95)=5.21 ; p<.001, d=0.71)$. No significant change from post-treatment to follow-up was observed for OCI-R, $t(205.13)=0.83, p=.409, d=0.11$; for BDI-II, $t(168.30)=-1.71, p=.089, d=-0.24$; and for BSI-GSI, $t(204.06)=-0.12, p=.903$, $d=-0.02$; (see Table 3). 
Table 3

Mean Differences and Effect Sizes From Pre-Treatment and Post-Treatment to Follow-up

\begin{tabular}{lcccccc}
\hline Measure & $\boldsymbol{n}_{\mathrm{FU}}$ & $\boldsymbol{M}_{\mathrm{FU}}(\boldsymbol{S D})$ & $\boldsymbol{M}_{\text {post }}(\boldsymbol{S D})$ & $\boldsymbol{d}_{\text {post-FU }}$ & $\boldsymbol{M}_{\text {pre }}(\boldsymbol{S D})$ & $\boldsymbol{d}_{\text {pre-FU }}$ \\
\hline Y-BOCS & 120 & $12.9(9.0)$ & $11.9(7.3)$ & -0.12 & $23.3(4.6)$ & 1.46 \\
OCI-R & 94 & $13.1(11.3)$ & $14.4(12.0)$ & 0.11 & $27.1(13.0)$ & 1.14 \\
BDI-II & 96 & $12.3(12.0)$ & $9.8(8.7)$ & -0.24 & $18.9(11.2)$ & 0.57 \\
BSI-GSI & 96 & $0.61(0.5)$ & $0.60(0.5)$ & -0.02 & $0.98(0.5)$ & 0.71 \\
\hline
\end{tabular}

Note. Y-BOCS = Yale-Brown Obsessive-Compulsive Scale interview score; OCI-R = Obsessive Compulsive Inventory - Revised; BDI-II = Beck Depression Inventory II; BSI-GSI = Global Severity Index of the Brief Symptom Inventory; pre = pre-treatment; post = post-treatment; FU = 1-year follow-up.

\section{Individual Improvement}

The course of symptoms from pre-treatment to post-treatment and follow-up was heterogeneous across patients (Figure $1 \mathrm{~b}$ ). Table 4 displays the numbers of patients with non-response, response without remission (response only), and remission at post-treatment and follow-up. Adopting the RCI for deterioration, Table 5 shows the numbers of participants with Y-BOCS score stability and deterioration at follow-up broken down by their outcome category at post-treatment. The relationship between outcome category (remission, response only, non-response) at post-treatment and stability at follow-up is illustrated in Figure $1 \mathrm{~b}$.

Table 4

Number of Non-Responders, Responders Without Remission and Remitters for Post-Treatment and Follow-up

\begin{tabular}{lcccc}
\hline & \multicolumn{2}{c}{ Outcome category at 1-year follow-up $\left(\mathbf{t}_{\mathrm{FU}}\right)$} & \\
\cline { 2 - 4 } Outcome category at $\mathbf{t}_{\text {post }}$ & No response & Response only & Remission & $\boldsymbol{\Sigma}_{\text {post }}$ \\
\hline No response & 27 & 3 & 7 & $37(30.8 \%)$ \\
Response only & 8 & 4 & 2 & $14(11.7 \%)$ \\
Remission & 8 & 9 & 52 & $69(57.5 \%)$ \\
$\sum_{\mathrm{FU}}$ & $43(35.8 \%)$ & $16(13.3 \%)$ & $61(50.8 \%)$ & $120(100 \%)$ \\
\hline
\end{tabular}

Note. Response only = Response without remission; post = post-treatment; FU = 1-year follow-up. 


\section{Table 5}

Change During Follow-up: Number of Stable and Deteriorated Participants at Follow-up Broken Down by Their Outcome Category at Post-Treatment

\begin{tabular}{lccc}
\hline & \multicolumn{2}{c}{ Change during 1-year follow-up $\left(\mathbf{t}_{\mathrm{FU}}\right)$} & \\
\cline { 2 - 3 } Outcome category at $\mathbf{t}_{\text {post }}$ & Stability & Deterioration & $\boldsymbol{\Sigma}_{\text {post }}$ \\
\hline No response & 34 & 3 & $37(30.8 \%)$ \\
Response only & 10 & 4 & $14(11,7 \%)$ \\
Remission & 66 & 3 & $69(57.5 \%)$ \\
$\sum_{\mathrm{FU}}$ & $110(91.7 \%)$ & $10(8.3 \%)$ & $120(100 \%)$ \\
\hline
\end{tabular}

Note. Response only = Response without remission; post = post-treatment; FU = 1-year follow-up.

\section{Prediction of Long-Term Outcomes}

Compared to remission, response only significantly predicted deterioration at follow-up $\left(B=2.17, S E=0.84, \chi^{2}(1)=6.58, p=.010\right.$, Odds Ratio $(\mathrm{OR})=8.8, \mathrm{CI}=1.71-50.65$, Wald $\chi^{2}=6.77, p=.009$ ). Nagelkerke's $R$-squared of this model was .174 (Hosmer-Lemeshow $R^{2}$ $=.137$, Cox-Snell $\left.R^{2}=.076\right)$. The inclusion of Y-BOCS scores at pre-treatment as predictor did not improve the model significantly, $B=0.13(S E=0.11), p=.235$. Initial Y-BOCS scores did not predict deterioration, $\mathrm{OR}=1.1\left(\mathrm{CI}=0.92-1.44\right.$, Wald $\left.\chi^{2}=1.41, p=.245\right)$.

\section{Cut-off Scores}

The Y-BOCS score at post-treatment that best predicted significant deterioration versus stability was 13 (sensitivity $=.70$; specificity $=.60$ ), indicating that participants with a score higher than or equal to 13 were more likely deteriorated at follow-up (see Figure 2a). Interestingly, the optimal cut-off score predicting sustained gains (relative to baseline) was 12 (sensitivity $=.83$; specificity $=.78$ ), suggesting that a Y-BOCS score of 12 or less at the time of treatment termination predicts sustained benefits at one year follow-up (see Figure 2b). 


\section{Figure 2}

Cut-off Points on the Y-BOCS

a

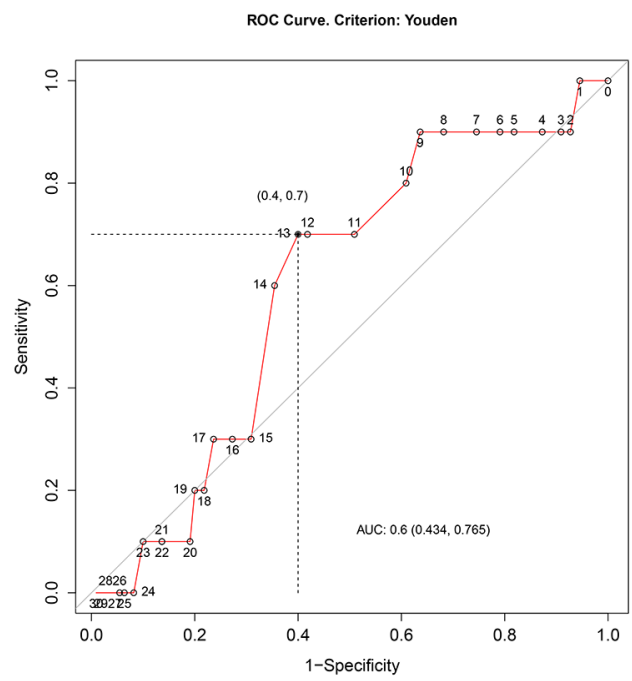

b

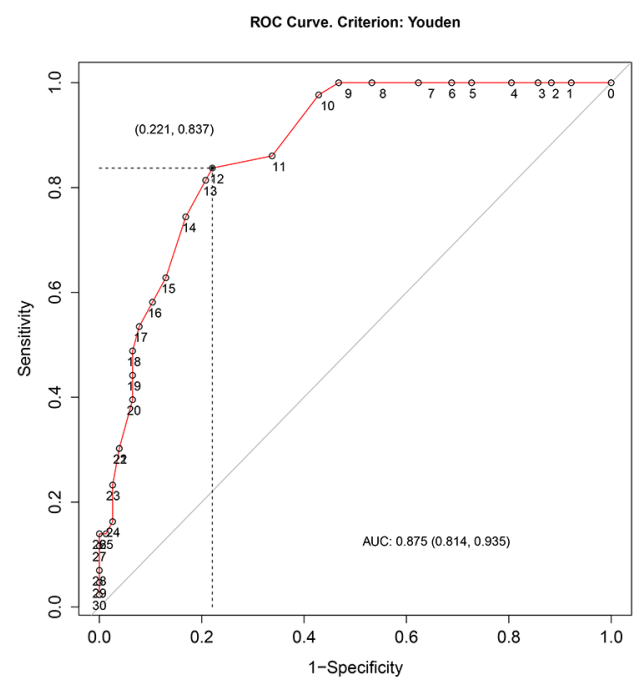

Note. Receiver-operating characteristic (ROC) curves with optimal cut-off points on the Y-BOCS at post-treatment to classify a) for deterioration (vs. stability) at follow-up and b) for sustained gains (response, remission, or both) at follow-up. AUC = Area under the ROC curve.

\section{Medication and Subsequent Outpatient Therapy}

Sixty-seven patients were free of psychotropic medications from post-treatment to follow-up. Twenty patients discontinued medications after post-treatment, but seven of them were again medicated at follow-up. Thirty patients were medicated continuously from post-treatment to follow-up. For three patients, data about medication at follow-up was missing. Most common were SSRIs $(n=33)$. A significant association between medication status (no medication, discontinued, discontinued and medicated again, continuously medicated) and outcome category at follow-up was observed ( $p=.015)$, with higher remission rates for medication-free patients and discontinuers $(61.2 \%$ and $69.2 \%)$ than for continuously medicated patients $(26.7 \%)$. No significant association could be observed for medication status and deterioration $(p=.402)$ at follow-up assessment.

Eighteen patients sought additional outpatient therapy of more than five sessions after post-treatment. Subsequent therapy was neither correlated with outcome category at post-treatment $(p=.067)$, nor at follow-up assessment $(p=.086)$, but at both assessment points, patients without remission sought additional therapy more frequently than remitters on a trend level. 


\section{Discussion}

The present study aimed to examine whether remission status and symptom levels at post-treatment are predictive for long-term stability of improvements after cognitive behavioral therapy for OCD. In addition, we intended to evaluate the general effectiveness of individual cognitive behavioral therapy in a sample of 120 patients by conducting a follow-up assessment one year after termination of treatment in routine clinical practice.

Applying the recently published Y-BOCS consensus criteria (Mataix-Cols et al., 2016) to classify patients as non-responders, responders, or remitters showed that response only at post-treatment was associated with a significantly higher likelihood for deterioration. Among the patients who benefited from CBT, those who achieved remission by the end of treatment had a considerably higher chance of maintaining initial improvement. Given the fact that stability and deterioration were defined by absence or presence of reliable changes (RCI), the criterion variable was not confounded with the consensus criteria. While similar findings have been shown in previous studies, these applied different remission criteria (Braga et al., 2005; Braga et al., 2010; Eisen et al., 2013). To our knowledge, the present findings are the first to show the predictive value of the consensually recommended Y-BOCS cut-off score, and thus confirm its validity in terms of long-term stability.

Considering that different cut-off scores have proven to predict long-term stability, we sought to determine a Y-BOCS score at post-treatment that best predicts deterioration versus stability one year later. Receiver-operating characteristic (ROC) curves pointed to a cut-off point of $\geq 13$ for classifying for future deterioration. As stability until follow-up may not be sufficient to assume long-term improvement, we finally determined a cut-off score to classify for sustained benefits at follow-up relative to pre-treatment. The resulting cut-off score of $\leq 12$ implies that patients with a Y-BOCS score of twelve or lower at post-treatment are likely to show long-term therapy benefits compared to patients with higher scores. Notably, the identified critical symptom levels are almost identical to the proposed expert consensus cut-off score for remission.

These findings highlight the utility of a Y-BOCS cut-off score of $\leq 12$ for defining remission status at post-treatment and add to previous evidence that subthreshold symptom severity protects patients with mental disorders from later deterioration (Braga et al., 2005; Braga et al., 2010; Judd et al., 1998; Paykel et al., 1995; Van Ameringen et al., 2003).

The results have implications for both etiological models and clinical practice. Different etiological models (Kalanthroff, Abramovitch, Steinman, Abramowitz, \& Simpson, 2016; Robbins, Gillan, Smith, de Wit, \& Ersche, 2012; Salkovskis, 1999) emphasize that compulsions contribute to the maintenance or worsening of symptoms. A reduction of symptom severity below a critical threshold may therefore weaken these dynamics. In clinical practice, the question of how to proceed if patients achieve response but not remission during the scheduled duration of psychotherapy is central. Ethical considerations may support continuation of treatment until remission is achieved. However, while 
there is research on treatment of non-responders to pharmacological therapy (Albert et al., 2018; Denys, van Megen, van der Wee, \& Westenberg, 2004; Pallanti, Hollander, \& Goodman, 2004), there is little data on the treatment of patients who failed to reach remission status during CBT.

As we observed large effect sizes for pre-post $(d=1.87)$ and pre-FU $(d=1.46)$ periods, we were able to confirm previous findings of long-term effectiveness of individual outpatient CBT in OCD (Cabedo et al., 2018; Hans \& Hiller, 2013; Hansen et al., 2019). Although our results suggest that reduced symptom levels are maintained from post-treatment to follow-up, we did observe a slight, non-significant increase in symptoms. Recurrence of OCD symptoms after treatment termination has been found in previous follow-up studies (Anderson \& Rees, 2007; Barrett, Healy-Farrell, \& March, 2004; Bolton \& Perrin, 2008), yet not consistently (Rufer et al., 2005). The slight increase in the present study may be explained by inferior long-term symptom stability of the small group of patients that achieved response without remission: while most patients who remitted $(75.4 \%)$ or did not respond $(73.0 \%)$ at post-treatment remained in the same outcome category at follow-up, only $28.6 \%$ of responders remained in this category one year later. Very few patients with response (without remission) at post-treatment achieve remission one year later (14.3\%), which illustrates again that response only at post-treatment indicates insufficient treatment.

One limitation of the present study stems from the treatment setting under routine conditions. Particularly, treatment did not follow a specific manual and therapy adherence was not controlled. The mean duration of therapy was longer than in most RCTs. Note, however, that "high intensity interventions" with more than 30 therapist-hours per patient have been found to yield superior effect sizes for treatment outcome compared to low and medium intensity (National Collaborating Centre for Mental Health, 2006). In the present study, the relatively long duration results from individual treatment planning, consideration of comorbid disorders, and termination of treatment on the basis of a consensual decision of patient and therapist. The duration is comparable to the average duration of outpatient psychotherapy in the public health care system in Germany (Lutz, Wittmann, Böhnke, Rubel, \& Steffanowski, 2012). Thus, our data derive from treatment conditions that are typical for the German and similar health care systems and may provide high ecological validity.

Sample size constitutes another limitation, as, at post-treatment, we observed only 14 patients in the category of response without remission, and only ten participants with deterioration at follow-up. Although, considering the large number of remitted patients that indicates an overall very successful treatment, larger sample sizes would increase the statistical power of predictions of critical subgroups. Future follow-up studies should also address life events, other therapies, and medications that may influence symptom stability. Furthermore, longer follow-up intervals might enable us to make conclusions about predictors of long-term treatment benefits. 
In summary, the present results suggest that the symptom level reached when terminating treatment is critical for the future course of illness. A post-treatment Y-BOCS score $<13$ optimally predicts higher individual likelihood for stability one year later. This cut-off almost perfectly fits with the expert consensus criterion for remission of OCD. Thus, such a remission criterion may be a useful instrument in aiding decision making in routine clinical practice, in particular for terminating or continuing treatment.

Funding: This research did not receive any specific grant from funding agencies in the public, commercial, or notfor-profit sectors.

Competing Interests: The authors have declared that no competing interests exist.

Acknowledgments: We thank Katharina Schwaiger for language editing.

\section{References}

Albert, U., Marazziti, D., Di Salvo, G., Solia, F., Rosso, G., \& Maina, G. (2018). A systematic review of evidence-based treatment strategies for obsessive-compulsive disorder resistant to first-line pharmacotherapy. Current Medicinal Chemistry, 25(41), 5647-5661.

https://doi.org/10.2174/0929867325666171222163645

Anderson, R. A., \& Rees, C. S. (2007). Group versus individual cognitive-behavioural treatment for obsessive-compulsive disorder: A controlled trial. Behaviour Research and Therapy, 45(1), 123-137. https://doi.org/10.1016/j.brat.2006.01.016

Bablas, V., Yap, K., Cunnington, D., Swieca, J., \& Greenwood, K. M. (2016). Mindfulness-based stress reduction for restless legs syndrome: A proof of concept trial. Mindfulness, 7(2), 396-408. https://doi.org/10.1007/s12671-015-0457-9

Barkham, M., Connell, J., Stiles, W. B., Miles, J. N., Margison, F., Evans, C., \& Mellor-Clark, J. (2006). Dose-effect relations and responsive regulation of treatment duration: The good enough level. Journal of Consulting and Clinical Psychology, 74(1), 160-167. https://doi.org/10.1037/0022-006X.74.1.160

Barrett, P., Healy-Farrell, L., \& March, J. S. (2004). Cognitive-behavioral family treatment of childhood obsessive-compulsive disorder: A controlled trial. Fournal of the American Academy of Child and Adolescent Psychiatry, 43(1), 46-62. https://doi.org/10.1097/00004583-200401000-00014

Beck, A. T., Steer, R. A., \& Brown, G. K. (1996). Beck depression inventory-II. San Antonio, TX, USA: The Psychological Corporation.

Bolton, D., \& Perrin, S. (2008). Evaluation of exposure with response-prevention for obsessive compulsive disorder in childhood and adolescence. Fournal of Behavior Therapy and Experimental Psychiatry, 39(1), 11-22. https://doi.org/10.1016/j.jbtep.2006.11.002 
Braga, D. T., Cordioli, A. V., Niederauer, K., \& Manfro, G. G. (2005). Cognitive-behavioral group therapy for obsessive-compulsive disorder: A 1-year follow-up. Acta Psychiatrica Scandinavica, 112(3), 180-186. https://doi.org/10.1111/j.1600-0447.2005.00559.x

Braga, D. T., Manfro, G. G., Niederauer, K., \& Cordioli, A. V. (2010). Full remission and relapse of obsessive-compulsive symptoms after cognitive-behavioral group therapy: A two-year followup. Revista Brasileira de Psiquiatria, 32(2), 164-168. https://doi.org/10.1590/S1516-44462010000200012

Cabedo, E., Carrió, C., \& Belloch, A. (2018). Stability of treatment gains 10 years after cognitive behavioral therapy for obsessive-compulsive disorder: A study in routine clinical practice. International fournal of Cognitive Therapy, 11(1), 44-57. https://doi.org/10.1007/s41811-018-0002-4

Denys, D., van Megen, H. J., van der Wee, N., \& Westenberg, H. G. (2004). A double-blind switch study of paroxetine and venlafaxine in obsessive-compulsive disorder. The fournal of Clinical Psychiatry, 65(1), 37-43. https://doi.org/10.4088/JCP.v65n0106

Derogatis, L. R., \& Melisaratos, N. (1983). The Brief Symptom Inventory: An introductory report. Psychological Medicine, 13(3), 595-605. https://doi.org/10.1017/S0033291700048017

Eisen, J. L., Sibrava, N. J., Boisseau, C. L., Mancebo, M. C., Stout, R. L., Pinto, A., \& Rasmussen, S. A. (2013). Five-year course of obsessive-compulsive disorder: Predictors of remission and relapse. The fournal of Clinical Psychiatry, 74(3), 233-239. https://doi.org/10.4088/JCP.12m07657

Falkenström, F., Josefsson, A., Berggren, T., \& Holmqvist, R. (2016). How much therapy is enough? Comparing dose-effect and good-enough models in two different settings. Psychotherapy, 53(1), 130-139. https://doi.org/10.1037/pst0000039

Farris, S. G., McLean, C. P., Van Meter, P. E., Simpson, H. B., \& Foa, E. B. (2013). Treatment response, symptom remission, and wellness in obsessive-compulsive disorder. The fournal of Clinical Psychiatry, 74(7), 685-690. https://doi.org/10.4088/JCP.12m07789

First, M. B., Gibbon, M., Spitzer, R. L., Williams, J. B., \& Benjamin, L. S. (1997). Structured Clinical Interview for DSM-IV® Axis II Personality Disorders SCID-II. Washington, DC, USA: American Psychiatric Publishing.

First, M. B., Spitzer, R. L., Gibbon, M., \& Williams, J. B. (1995). Structured Clinical Interview for DSMIV Axis I Disorders. New York, NY, USA: New York State Psychiatric Institute.

Foa, E. B., Huppert, J. D., Leiberg, S., Langner, R., Kichic, R., Hajcak, G., \& Salkovskis, P. M. (2002). The Obsessive-Compulsive Inventory: Development and validation of a short version. Psychological Assessment, 14(4), 485-496. https://doi.org/10.1037/1040-3590.14.4.485

Goodman, W. K., Price, L. H., Rasmussen, S. A., Mazure, C., Delgado, P., Heninger, G. R., \& Charney, D. S. (1989a). The Yale-Brown Obsessive Compulsive Scale. II. Validity. Archives of General Psychiatry, 46(11), 1012-1016. https://doi.org/10.1001/archpsyc.1989.01810110054008

Goodman, W. K., Price, L. H., Rasmussen, S. A., Mazure, C., Fleischmann, R. L., Hill, C. L., . . Charney, D. S. (1989b). The Yale-Brown Obsessive Compulsive Scale. I. Development, use, and reliability. Archives of General Psychiatry, 46(11), 1006-1011.

https://doi.org/10.1001/archpsyc.1989.01810110048007 
Guy, W. (1976). Clinical Global Impression, ECDEU assessment manual for psychopharmacology. Rockville, MD, USA: US Dept. of Health, Education, and Welfare.

Han, X., Geffen, S., Browning, M., Kenardy, J., \& Geffen, G. (2011). Outcome evaluation of a multidisciplinary pain management programme comparing group with individual change measures. Clinical Psychologist, 15(3), 133-138. https://doi.org/10.1111/j.1742-9552.2011.00032.x

Hand, I., \& Büttner-Westphal, H. (1991). Die Yale-Brown Obsessive Compulsive scale (Y-BOCS): Ein halbstrukturiertes Interview zur Beurteilung des Schweregrades von Denk- und Handlungszwängen. Verhaltenstherapie, 1(3), 223-225. https://doi.org/10.1159/000257972

Hans, E., \& Hiller, W. (2013). A meta-analysis of nonrandomized effectiveness studies on outpatient cognitive behavioral therapy for adult anxiety disorders. Clinical Psychology Review, 33(8), 954-964. https://doi.org/10.1016/j.cpr.2013.07.003

Hansen, B., Kvale, G., Hagen, K., Havnen, A., \& Öst, L.-G. (2019). The Bergen 4-day treatment for OCD: Four years follow-up of concentrated ERP in a clinical mental health setting. Cognitive Behaviour Therapy, 48(2), 89-105. https://doi.org/10.1080/16506073.2018.1478447

Hiller, W., Schindler, A., Andor, T., \& Rist, F. (2011). Vorschläge zur Evaluation regulärer Psychotherapien an Hochschulambulanzen im Sinne der Phase-IV-Therapieforschung. Zeitschrift für Klinische Psychologie und Psychotherapie, 40, 22-32. https://doi.org/10.1026/1616-3443/a000063

Hohagen, F., Wahl-Kordon, A., Lotz-Rambaldi, W., \& Muche-Borowski, C. (2014). S3-Leitlinie Zwangsstörungen. Berlin, Germany: Springer.

Jacobson, N. S., Follette, W. C., \& Revenstorf, D. (1984). Psychotherapy outcome research: Methods for reporting variability and evaluating clinical significance. Behavior Therapy, 15(4), 336-352. https://doi.org/10.1016/S0005-7894(84)80002-7

Jacobson, N. S., \& Truax, P. (1991). Clinical significance: A statistical approach to defining meaningful change in psychotherapy research. Journal of Consulting and Clinical Psychology, 59(1), 12-19. https://doi.org/10.1037/0022-006X.59.1.12

Jones, S. H., Thornicroft, G., Coffey, M., \& Dunn, G. (1995). A brief mental health outcome scalereliability and validity of the Global Assessment of Functioning (GAF). The British fournal of Psychiatry, 166(5), 654-659. https://doi.org/10.1192/bjp.166.5.654

Judd, L. L., Akiskal, H. S., Maser, J. D., Zeller, P. J., Endicott, J., Coryell, W., . . Keller, M. B. (1998). Major depressive disorder: A prospective study of residual subthreshold depressive symptoms as predictor of rapid relapse. Fournal of Affective Disorders, 50(2-3), 97-108. https://doi.org/10.1016/S0165-0327(98)00138-4

Kalanthroff, E., Abramovitch, A., Steinman, S. A., Abramowitz, J. S., \& Simpson, H. B. (2016). The chicken or the egg: What drives OCD? Journal of Obsessive-Compulsive and Related Disorders, 11, 9-12. https://doi.org/10.1016/j.jocrd.2016.07.005

Kraus, D. R., Castonguay, L., Boswell, J. F., Nordberg, S. S., \& Hayes, J. A. (2011). Therapist effectiveness: Implications for accountability and patient care. Psychotherapy Research, 21(3), 267-276. https://doi.org/10.1080/10503307.2011.563249 
Lampert, T., \& Kroll, L. E. (2009). Die Messung des sozioökonomischen Status in sozialepidemiologischen Studien. In M. Richter \& K. Hurrelmann (Eds.), Gesundheitliche Ungleichheit (pp. 309-334). https://doi.org/10.1007/978-3-531-91643-9_18

López-Ratón, M., Rodríguez-Álvarez, M. X., Cadarso-Suárez, C., \& Gude-Sampedro, F. (2014). OptimalCutpoints: An R package for selecting optimal cutpoints in diagnostic tests. fournal of Statistical Software, 61(8), 1-36. https://doi.org/10.18637/jss.v061.i08

Lutz, W., Wittmann, W. W., Böhnke, J. R., Rubel, J., \& Steffanowski, A. (2012). Zu den Ergebnissen des Modellprojektes der Techniker-Krankenkasse zum Qualitätsmonitoring in der ambulanten Psychotherapie aus Sicht des wissenschaftlichen Evaluationsteams. PPmP-Psychotherapie . Psychosomatik · Medizinische Psychologie, 62(11), 413-417. https://doi.org/10.1055/s-0032-1327565

Mataix-Cols, D., Fernandez de la Cruz, L., Nordsletten, A. E., Lenhard, F., Isomura, K., \& Simpson, H. B. (2016). Towards an international expert consensus for defining treatment response, remission, recovery and relapse in obsessive-compulsive disorder. World Psychiatry, 15(1), 80-81. https://doi.org/10.1002/wps.20299

Moritz, S., Meier, B., Kloss, M., Jacobsen, D., Wein, C., Fricke, S., \& Hand, I. (2002). Dimensional structure of the Yale-Brown Obsessive-Compulsive Scale (Y-BOCS). Psychiatry Research, 109(2), 193-199. https://doi.org/10.1016/S0165-1781(02)00012-4

National Collaborating Centre for Mental Health. (2006). Obsessive-compulsive disorder: Core interventions in the treatment of obsessive-compulsive disorder and body dysmorphic disorder (National Clinical Practice Guideline Number 31). Leicester, United Kingdom: British Psychological Society and The Royal College of Psychiatrists.

Olatunji, B. O., Davis, M. L., Powers, M. B., \& Smits, J. A. J. (2013). Cognitive-behavioral therapy for obsessive-compulsive disorder: A meta-analysis of treatment outcome and moderators. fournal of Psychiatric Research, 47(1), 33-41. https://doi.org/10.1016/j.jpsychires.2012.08.020

Öst, L. G., Havnen, A., Hansen, B., \& Kvale, G. (2015). Cognitive behavioral treatments of obsessivecompulsive disorder: A systematic review and meta-analysis of studies published 1993-2014. Clinical Psychology Review, 40, 156-169. https://doi.org/10.1016/j.cpr.2015.06.003

Pallanti, S., Hollander, E., \& Goodman, W. K. (2004). A qualitative analysis of nonresponse: Management of treatment-refractory obsessive-compulsive disorder. The fournal of Clinical Psychiatry, 65(Suppl 14), 6-10.

Paykel, E. S., Ramana, R., Cooper, Z., Hayhurst, H., Kerr, J., \& Barocka, A. (1995). Residual symptoms after partial remission: An important outcome in depression. Psychological Medicine, 25(6), 1171-1180. https://doi.org/10.1017/S0033291700033146

Robbins, T. W., Gillan, C. M., Smith, D. G., de Wit, S., \& Ersche, K. D. (2012). Neurocognitive endophenotypes of impulsivity and compulsivity: Towards dimensional psychiatry. Trends in Cognitive Sciences, 16(1), 81-91. https://doi.org/10.1016/j.tics.2011.11.009

Rufer, M., Hand, I., Alsleben, H., Braatz, A., Ortmann, J., Katenkamp, B., . . Peter, H. (2005). Longterm course and outcome of obsessive-compulsive patients after cognitive-behavioral therapy in combination with either fluvoxamine or placebo: A 7-year follow-up of a randomized 
double-blind trial. European Archives of Psychiatry and Clinical Neuroscience, 255(2), 121-128. https://doi.org/10.1007/s00406-004-0544-8

Salkovskis, P. M. (1999). Understanding and treating obsessive-compulsive disorder. Behaviour Research and Therapy, 37(Suppl 1), S29-S52. https://doi.org/10.1016/S0005-7967(99)00049-2

Van Ameringen, M., Allgulander, C., Bandelow, B., Greist, J. H., Hollander, E., Montgomery, S. A., ... Swinson, R. P. (2003). WCA recommendations for the long-term treatment of social phobia. CNS Spectrums, 8(8, Suppl. 1), 40-52. https://doi.org/10.1017/S1092852900006933

Youden, W. J. (1950). Index for rating diagnostic tests. Cancer, 3(1), 32-35. https://doi.org/10.1002/1097-0142(1950)3:1<32::AID-CNCR2820030106>3.0.CO;2-3

\section{EACLIPT}

Clinical Psychology in Europe (CPE) is the official journal of the European Association of Clinical Psychology and Psychological Treatment (EACLIPT).

\section{(4) leibniz-psychology.org}

PsychOpen GOLD is a publishing service by Leibniz Institute for Psychology Information (ZPID), Germany. 